\title{
Association of preeclampsia with infant APOL1 genotype in African Americans
}

\author{
Anna K. Miller', Timur Azhibekov², John F. O'Toole ${ }^{3}$, John R. Sedor ${ }^{3,4}$, Scott M. Williams ${ }^{1,5}$, \\ Raymond W. Redline ${ }^{6}$ and Leslie A. Bruggeman ${ }^{3^{*}}$ (i)
}

\begin{abstract}
Background: Black women in the United States and Africa are at an increased risk for preeclampsia. Allelic variants in the gene for apolipoprotein $\mathrm{LI}, A P O L 1$, are found only in populations of African ancestry, and have been shown to contribute significant risk for kidney disease. Recent studies suggest these APOL1 variants also may contribute risk for preeclampsia.

Methods: The association of preeclampsia with carriage of APOL 1 risk alleles was evaluated in a case-control study of deliveries from black women at a single center in Cleveland, Ohio that included gross and histopathologic evaluations of placental tissues (395 cases and 282 controls). Using logistic regression models, associations between fetal APOL 1 genotype and preeclampsia were evaluated using several case definitions based on prematurity and severity of preeclampsia, with uncomplicated term pregnancies as controls. Associations between APOL1 genotype and pathological features were also examined.

Results: The infant APOL1 genotype was significantly associated with preeclampsia in a dominant inheritance pattern with odds ratio of $1.41(P=0.029,95 \% \mathrm{Cl} 1.037,1.926)$. Stratifying preeclampsia cases by preterm birth, significant associations were detected for both recessive (O.R. $=1.70, P=0.038)$ and additive (O.R. $=1.33, P=0.028)$ inheritance patterns. APOL 1 genotype, however, was not significantly associated with pathological changes or other perinatal observations.

Conclusions: Preeclampsia appears to be another disease associated with APOL1 variants, however, further studies are needed to increase confidence in the mode of inheritance. By understanding the association of APOL1 variants with preeclampsia, genetic screening tests for APOL 1 may be useful to predict at-risk pregnancies and targeted interventions may be developed to improve pregnancy outcomes.
\end{abstract}

Keywords: African American, Genetics, Pathology, Placenta, Preeclampsia

\section{Background}

Preeclampsia (PE) is a common complication of pregnancy and occurs more frequently in women of African ancestry (reviewed in $[1,2])$. PE prevalence ranges from $3-8 \%$ in developed countries and as high as $26 \%$ in sub-Saharan African countries, and African American women are three times more likely to die from PE compared to European Americans. The American College of Obstetricians and

\footnotetext{
* Correspondence: leslie.bruggeman@case.edu

${ }^{3}$ Departments of Inflammation and Immunity and Nephrology, Cleveland Clinic, Case Western Reserve University School of Medicine, Cleveland, USA Full list of author information is available at the end of the article
}

Gynecologists [3] defines PE as new onset hypertension of $\geq 140 \mathrm{mmHg}$ systolic or $\geq 90 \mathrm{mmHg}$ diastolic along with proteinuria or other end organ dysfunction. A separate class of $\mathrm{PE}$ is defined as severe PE with blood pressures $\geq 160$ / $110 \mathrm{mmHg}$ and proteinuria or other end organ dysfunction. $\mathrm{PE}$ is a heterogeneous disorder, with differences in clinical presentation and outcomes for early onset PE (placental type) in which symptoms occur before 34 weeks gestation, and late onset PE (maternal type) in which symptoms occur $\geq 34$ weeks gestation (reviewed in [4]).

Like PE, chronic kidney disease (CKD) also is more prevalent in African Americans, and the recent description

(c) The Author(s). 2020 Open Access This article is licensed under a Creative Commons Attribution 4.0 International License, which permits use, sharing, adaptation, distribution and reproduction in any medium or format, as long as you give appropriate credit to the original author(s) and the source, provide a link to the Creative Commons licence, and indicate if changes were made. The images or other third party material in this article are included in the article's Creative Commons licence, unless indicated otherwise in a credit line to the material. If material is not included in the article's Creative Commons licence and your intended use is not permitted by statutory regulation or exceeds the permitted use, you will need to obtain permission directly from the copyright holder. To view a copy of this licence, visit http://creativecommons.org/licenses/by/4.0/ The Creative Commons Public Domain Dedication waiver (http://creativecommons.org/publicdomain/zero/1.0/) applies to the data made available in this article, unless otherwise stated in a credit line to the data. 
of two polymorphisms in the APOL1 gene has advanced our understanding of the increased risk for CKD in African Americans (reviewed in [5]). APOL1-associated CKD risk is inherited as a recessive trait, and a high risk genotype is any combination of the two APOL1 risk alleles known as G1 (rs73885319, p.S342G and rs60910145, p.I384M) and G2 (rs71785313, p.NYK388K), with the common alleles at each site not associated with CKD referred to as G0. APOL1 is better known as the trypanolytic factor in human serum and provides innate immunity against Trypanosoma brucei brucei infection [6]. The G1 and G2 variants are more recent evolutionary adaptations that extend immune protection (in a dominant inheritance pattern) against T. $b$. rhodesiense and T. b. gambiense infections as causes of African sleeping sickness. The G1 and G2 variants are absent in individuals without recent African ancestry.

APOL1 is expressed in several organs, most predominantly the liver, which secretes the abundant circulating APOL1 that kills trypanosomes. APOL1 also is expressed (but not secreted) by several other tissues including the kidney [7, 8] and placenta (trophoblasts) [9-12]. The function of this intracellular APOL1 to homeostatic and pathogenic processes is not fully understood. Since a functional APOL1 gene is present only in some primates, we created transgenic mice to model the expression of intracellular APOL1. These mice unexpectedly developed PE or eclamptic seizures and had small litter sizes from both fetal and neonatal deaths, both of which were independent of an underlying CKD [12]. The occurrence of PE/eclampsia was dependent on the APOL1 genotype of the pup, not the dam, indicating transgenic $A P O L 1$ expressed by the fetus or placenta triggered these phenotypes.

In humans, several studies have suggested APOL1 expression may contribute to pregnancy complications including PE [13-15]. Although prior genome wide association studies have not identified $A P O L 1$ risk alleles as candidates for PE, these studies had limitations such as excluding individuals of African ancestry, not examining informative markers for the $A P O L 1$ variants, or only genotyping the mother and not the child [16-19]. In reports specifically evaluating APOL1 risk alleles effects, association studies from pediatric cohorts found children with glomerular disease had a higher prevalence of preterm birth and low birth weight if they had two APOL1 risk variants [20], although this association was not replicated in children without CKD [21]. A recent study of mother-child dyads from independent cohorts in New York and Tennessee associated PE (O.R.=1.84 and 1.92 respectively) with a recessive inheritance of $A P O L 1$ risk variants in the child but not the mother [22].

To further establish association of PE with APOL1 risk alleles in the infant, and to assess correlates with placental pathology, we examined an archival collection of placental tissues from black women in the Cleveland area.
Genotyping of infant tissue confirmed an association of APOL1 risk alleles with $\mathrm{PE}$, although this association was most significant under a dominant inheritance pattern. Examining preterm PE cases separately, the association with APOL1 genotype was significant in both recessive and additive models. Although the PE cases exhibited typical pathology consistent with a PE diagnosis and prematurity, there were no specific pathological features that correlated with APOL1 genotype.

\section{Methods \\ Study population}

The Ohio March of Dimes biobank is a single center, ten year collection (2005-2014) of 8006 singleton pregnancies in which placentas, umbilical cords, and fetal membranes were collected for pathological evaluation, including normal term pregnancies. It excluded cases of congenital malformations, genetic disorders, and infections associated with congenital anomalies. The biobank is linked with a dataset (Supplemental Table 1) of maternal medical history, demographics, previous pregnancy history, and clinical data from the current pregnancy including early and late antenatal periods, intrapartum and birth data, and initial neonatal observations. In addition, gross placental measurements and standardized histopathologic diagnoses were recorded according to the Amsterdam Placenta Working Group definitions [23]. Since $A P O L 1$ risk variants are only found in individuals of African ancestry, the study cohort was limited to women who self-identified as black (African American) and included both full term ( $\geq 37$ weeks) and preterm ( $>20$ to $<37$ weeks) spontaneous and elective deliveries. Controls were self-identified black women with full term pregnancies and no history of PE or other significant antenatal condition whose placentas were submitted to pathology for other indications. PE diagnosis and severity was specified by the submitting physician using criteria standardized by the American College of Obstetricians and Gynecologists [3]. PE severity was classified as either nototherwise-specified (NOS) based on blood pressure $\geq 140$ to $<160 \mathrm{mmHg}$ systolic or $\geq 90$ to $<110 \mathrm{mmHg}$ diastolic or severe for cases with blood pressure $\geq 160 \mathrm{mmHg}$ systolic or $\geq 110 \mathrm{mmHg}$ diastolic.

\section{Genotyping}

Archived samples from the Ohio March of Dimes biobank were used for fetal genomic DNA extraction (Qiagen RecoverAll Total Nucleic Acid Isolation Kit) from two, $10 \mu \mathrm{m}$ sections of formalin-fixed, paraffin embedded umbilical cords. A TaqMan allele discrimination assay (ThermoFisher Scientific) was used to identify the two CKD-associated APOL1 risk alleles as previously described for polymorphisms rs73885319 (representing the G1 allele) and a rs71785313 (G2 allele) [24]. 


\section{Statistical analysis}

Summary statistics were performed by clinical category, comparing to term controls: all $\mathrm{PE}$ cases, preterm $\mathrm{PE}$ cases, term PE cases, term PE cases classified as NOS, term PE cases classified as severe. Summary statistics were performed for maternal risk factors, pathological features, and APOL1 genotype. Unadjusted and adjusted logistic regression models were used to assess the association between $A P O L 1$ variants and all PE cases and the subtypes described above. A forward stepwise selection procedure was used to determine the clinical/pathological variables that were included in adjusted models. For categories with a sample size of less than five cases with the scored feature, combined analyses were used or not done. APOL1 genotype was examined for dominant, recessive, or additive inheritance models. The association between APOL1 and pathological features were tested within clinical categories using a global chi-square and compared by dominant, recessive, or additive inheritance pattern. Pathological features were tested for association with APOL1 by chi-square and ANOVA for categorical and continuous variables respectively. All analyses were performed in $\mathrm{R}$ version 3.5.1. The primary dataset generated and analyzed for this study is included as supplementary information (supplemental Primary Dataset).

\section{Results}

The study population selected from the March of Dimes biobank consisted of 395 PE cases with 282 control pregnancies. Study inclusion/exclusion criteria are detailed in Supplemental Table 2; of note, HELLP syndrome (hemolysis, elevated liver enzymes, low platelet count) and comorbid conditions associated with PE risk such as gestational diabetes and pre-pregnancy hypertension were excluded. There were significant differences between controls and cases for maternal age and gravidity (Table 1). As expected for births complicated by $\mathrm{PE}$, there were significant differences in gestational age, birth weight, and placenta weights. Both term and preterm cases had significantly lower birth weights. Placental weights were similar between controls and term cases, but significantly lower in preterm cases. Fetal/ placental weight ratios, an indicator of placental efficiency, were significantly lower in both preterm and term cases.

\section{APOL1 genotype and allele frequencies}

APOL1 allele and genotype frequencies from PE pregnancies were compared to uncomplicated term pregnancies using umbilical cord tissue, reflecting the infant's genome. APOL1 genotype frequencies did not deviate from Hardy-Weinberg equilibrium in controls or any case category $(P>0.05)$. The control group genotype frequencies (Table 2) of 0,1 , or 2 risk alleles $(47 \%, 40 \%$, $13 \%$ respectively) were near reported genotype frequencies in African Americans of 40\%, 46\%, 14\% [25]. Similarly, the control group allele frequencies (Table 2) for G0, G1 and G2 (67\%, 23\%, and 10\% respectively) did not differ significantly from reported general population frequencies of $62-65 \%, 22-23 \%$, and $13-15 \%$ (summarized in [24]). There was an enrichment of one risk allele and two risk allele genotypes in PE cases. These differences in APOL1 genotype between cases and controls were analyzed by logistic regression models for recessive, additive, and dominant inheritance patterns.

\section{Association between PE and APOL1 genotype by logistic regression modeling}

For regression modeling, pathological features were evaluated for potential adjustment as covariates. The presence and severity of placental pathology were compared between all case definitions with control pregnancies by chi-square analyses (Supplemental Table 3). PE cases (all, and stratified as term or preterm) were significant for the presence of villous infarcts. Infarction-hematomas (also known as round intraplacental hematomas), considered to represent intraplacental abruptions [26, 27], also were significantly more common in the preterm cases. The overall placental maturity based on the microscopic villous architecture (referred to as "villous architecture maturity") was considered in conjunction with gestational age based on the term and preterm designations. The term cases were not significantly different than the control group. As expected, the preterm cases were more

Table 1 Demographics of study population and case subgroups, mean (SD)

\begin{tabular}{|c|c|c|c|c|c|c|c|}
\hline & $\begin{array}{l}\text { Controls } \\
n=282\end{array}$ & $\begin{array}{l}\text { All cases } \\
n=395\end{array}$ & $p^{*}$ & $\begin{array}{l}\text { Case Term } \\
n=204\end{array}$ & $\begin{array}{l}\text { Cases Preterm } \\
n=191\end{array}$ & $\begin{array}{l}\text { Cases Term NOS } \\
n=58\end{array}$ & $\begin{array}{l}\text { Cases Term severe } \\
n=146\end{array}$ \\
\hline Maternal age, year & $21.7(4.4)$ & $23.6(5.5)$ & $<0.001$ & $23.4(5.7)$ & $23.9(5.4)$ & $23.6(4.9)$ & $23.3(6.0)$ \\
\hline Gravidity (median) & 1 & 2 & $<0.001$ & 2 & 2 & 2 & 2 \\
\hline Gestational age, week & $39.4(1.2)$ & $36.4(3.5)$ & $<0.001$ & $38.9(1.2)$ & $33.7(3.2)$ & $39.1(1.2)$ & $38.8(1.2)$ \\
\hline Birth weight, g & $3146(516)$ & $2548(762)$ & $<0.001$ & $2997(525)$ & $2008(642)$ & 3052 (474) & $2977(543)$ \\
\hline Fetal/placental weight & $7.7(4.8)$ & $6.6(1.3)$ & 0.001 & $7.0(1.2)$ & $6.0(1.2)$ & $6.8(1.0)$ & $7.1(1.2)$ \\
\hline Placental weight, g & $451(201)$ & 385 (119) & $<0.001$ & $437(91)$ & $329(121)$ & $455(78)$ & $430(95)$ \\
\hline
\end{tabular}

*Controls versus all cases. Gestational age data stratified by APOL1 genotype are shown in Fig. 1. 
Table 2 APOL 1 alleles and genotype frequencies

\begin{tabular}{llllllll}
\hline & & Controls & All Cases & Cases Term & Cases Preterm & Cases Term NOS & Cases Term severe \\
\hline Allele Frequency & G0 & $377(67 \%)$ & $488(62 \%)$ & $263(64 \%)$ & $225(59 \%)$ & $75(65 \%)$ & $188(64 \%)$ \\
& G1 & $132(23 \%)$ & $203(26 \%)$ & $103(25 \%)$ & $100(26 \%)$ & $30(26 \%)$ & $73(25 \%)$ \\
Genotype Frequency & $55(10 \%)$ & $99(13 \%)$ & $42(11 \%)$ & $57(14 \%)$ & $11(9 \%)$ & $31(11 \%)$ \\
& G2 risk allele & $132(47 \%)$ & $153(39 \%)$ & $79(39 \%)$ & $72(38 \%)$ & $23(40 \%)$ & $58(40 \%)$ \\
& 1 risk allele & $113(40 \%)$ & $182(46 \%)$ & $101(50 \%)$ & $81(42 \%)$ & $29(50 \%)$ & $72(49 \%)$ \\
& 2 risk allele & $37(13 \%)$ & $60(15 \%)$ & $22(11 \%)$ & $38(19 \%)$ & $6(10 \%)$ & $16(11 \%)$ \\
\hline
\end{tabular}

immature and significantly different than the controls. The differences in both infarction-hematomas and the villous architecture maturity in the preterm cases was the main contributor to the significant differences in the all cases group, as these were not significantly different in the term cases. All other pathological features were not significantly different between PE cases and controls.

In an unadjusted logistic regression model (Table 3), the association of the APOL1 genotype with PE (all cases) was only significant in a dominant inheritance pattern with an O.R.=1.41. No other mode of inheritance was significant.

Three additional models were examined adjusting for pathological features and cohort characteristics that were different between cases and controls using a forward stepwise selection procedure. Model 1 (Supplemental Table 4A) adjusted for maternal age, Model 2 (Supplemental Table 4B) adjusted for maternal age and villous architecture maturity, and Model 3 (Supplemental Table 4C) adjusted for maternal age, villous architecture maturity, and gravidity. In all adjusted Models, the association between APOL1 genotype and PE (all cases) remained significant for the dominant inheritance pattern with an O.R.=1.40 to 1.43 .

When cases were stratified by prematurity or severity of PE, the significance of the APOL1 genotype association varied by mode of inheritance. In all models except Model 1, preterm PE cases were significant for a recessive inheritance pattern with O.R. $=1.70$ to 1.76 . In all models except Model 3, the preterm PE cases also were significant in an additive inheritance pattern (O.R. $=1.32$ to 1.35 ). For the term PE cases, no association was significant in all models and for any mode of inheritance, including when stratified by NOS or severe PE. In all adjusted models, inclusion of these variables had minimal effect on odds ratios.

\section{Association of APOL1 genotype with pathology}

Pathologic features also were analyzed by mode of inheritance of APOL1 alleles (Supplemental Tables 5A and 5B). There were no features that associated with any inheritance pattern by case status. Gestational age, which was significantly different between cases and controls (Table 1), was not significantly different based on APOL1 genotype within any case definition (Fig. 1). In addition, clinical observations and pathological features were analyzed for associations with the number of APOL1 risk alleles (Supplemental Table 6). None of the clinical or pathological factors differed based on APOL1 genotype alone.

\section{Discussion}

Although the underlying causes for PE are multifactorial, genetic factors have been recognized as likely contributors to PE risk. A recent report by Reidy et al. [22] genotyped APOL1 risk variants in two geographically distinct cohorts and attributed PE risk with a recessive inheritance of APOL1 risk alleles in the infant, but not the mother. Our observations are consistent with this report, however, the mode of inheritance in our study was most significant for dominant inheritance in all cases. Only our preterm PE cases were significant for a recessive inheritance pattern, at a similar odds ratio as reported in the Reidy et al. study. We did not find an association between APOL1 genotype and the gestational age at time of birth, severity of $\mathrm{PE}$, or changes in pathology which also is consistent with Reidy et al. study. Our cohort excluded cases of HELLP syndrome and history of diabetes or hypertension, and morbid obesity. The Reidy et al. cohorts did not exclude these conditions, however their APOL1 genotype associations were not influenced by these variables.

Table 3 PE association with fetal APOL1 genotype: Unadjusted model

\begin{tabular}{|c|c|c|c|c|c|c|c|c|c|}
\hline & \multicolumn{3}{|c|}{ Dominant model } & \multicolumn{3}{|c|}{ Recessive model } & \multicolumn{3}{|c|}{ Additive model } \\
\hline & $\mathrm{OR}$ & $95 \% \mathrm{Cl}$ & $P$ & $\overline{O R}$ & $95 \% \mathrm{Cl}$ & $P$ & $\overline{O R}$ & $95 \% \mathrm{Cl}$ & $P$ \\
\hline All Cases & 1.41 & $1.037,1.926$ & 0.029 & 1.22 & $0.788,1.923$ & 0.373 & 1.23 & $0.990,1.542$ & 0.063 \\
\hline Term cases & 1.38 & $0.961,1.998$ & 0.082 & 0.83 & $0.464,1.442$ & 0.507 & 1.13 & $0.869,1.476$ & 0.358 \\
\hline Preterm cases & 1.44 & $0.994,2.102$ & 0.055 & 1.70 & $1.030,2.801$ & 0.038 & 1.33 & $1.033,1.728$ & 0.028 \\
\hline Term cases, NOS & 1.36 & $0.768,2.441$ & 0.297 & 0.79 & $0.287,1.844$ & 0.611 & 1.10 & $0.725,1.639$ & 0.659 \\
\hline Term cases, Severe & 1.39 & $0.930,2.099$ & 0.109 & 0.84 & $0.439,1.548$ & 0.588 & 1.14 & $0.854,1.528$ & 0.368 \\
\hline
\end{tabular}




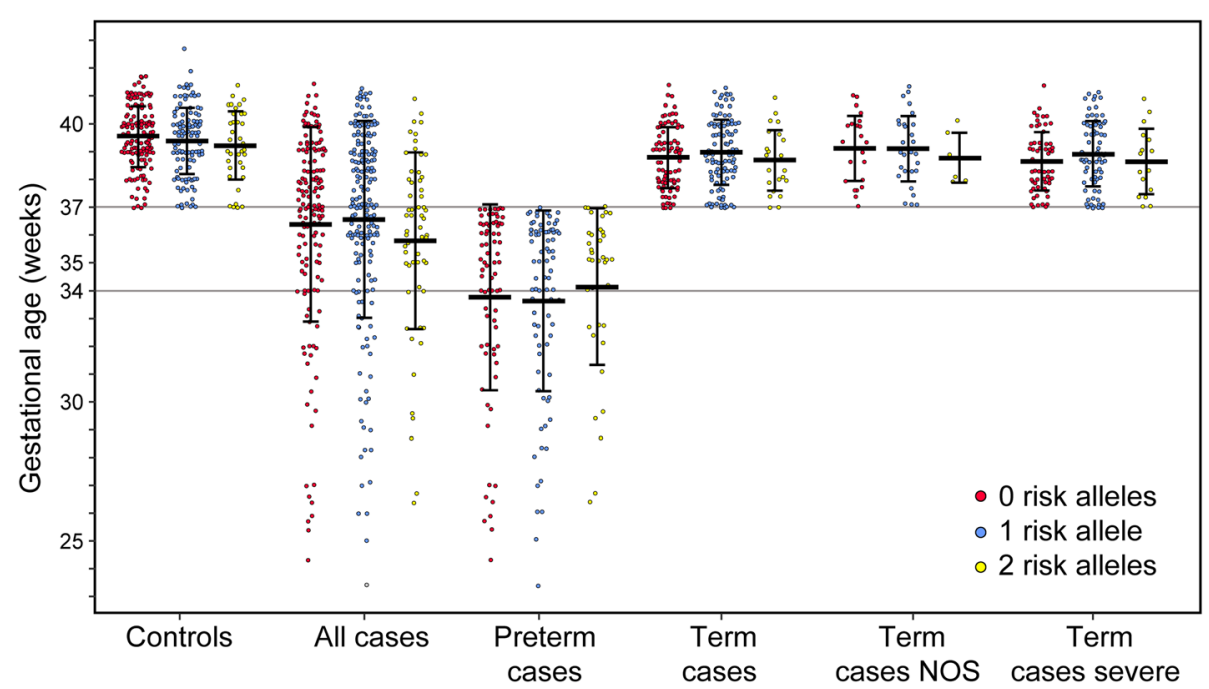

Fig. 1 No difference in gestational age based on APOL1 genotype. Preterm was defined as less than 37 weeks gestation, and early onset PE is before 34 weeks gestation. Although our cohort only recorded time of delivery and not onset of PE symptoms, all deliveries prior to 34 weeks would be from early onset PE. Controls versus all cases and preterm cases were significantly different $(P<0.001)$, but there was no difference in gestation age within each case definition by APOL1 genotype. Data are mean \pm SD

Our study did not observe a significant association of APOL1 genotype with any scored pathologic feature at delivery. This lack of association could indicate the APOL1-dependent mechanism is not directly linked to decreased endovascular invasion by trophoblasts and inadequate spiral arteriolar remodeling, and that the causal event mediated by APOL1 is not limited to the subgroup of $\mathrm{PE}$ associated with severe placental maternal vascular malperfusion (i.e. ischemic placenta). However, this may not exclude a unique role for APOL1 in inducing a novel process in trophoblasts earlier in pregnancy, which then becomes a critical factor for the failed trophoblast invasion, subsequently initiating the typical cascade of events from placental ischemia to PE. The clinical heterogeneity of $\mathrm{PE}$ is related to both placental gene expression and placental histopathology $[28,29]$, and pathogenesis is multifactorial and frequently dependent on the maternal response to reach a threshold for the toxic systemic vascular reaction [30]. Our APOL1 mouse models may provide an experimental platform to assess these issues throughout pregnancy, including the timing of trophoblast APOL1 expression, characterization of placental gene expression patterns, maldevelopment of typical placental structures, and systemic maternal responses.

Overall, our observations are consistent with the original observation in Reidy et al. that fetal APOL1 risk alleles contribute to PE risk, however, additional questions remain, specifically regarding the inheritance pattern when considering gestational age. Different genetic models apply to the various disease susceptibilities associate with APOL1 risk alleles (i.e. CKD risk is recessive, protection against trypanosomiasis is dominant), thus additional investigations are needed in both African American and African populations to establish the inheritance pattern for PE. It is possible there is a phenotypic difference in PE that occurs prior to 37 weeks gestation. In addition, it is possible there is a phenotypic difference with the carriage of the G1 versus G2 alleles. Since we were unable to genotype the mothers, another aspect of this study that could not be addressed is a possible discordance of APOL1 alleles between mother and infant as a key part of the genotypic risk.

Some limitations of our study are similar to the Reidy et al. report, including the use of cohorts from other investigations that was not originally designed to examine the effects of maternal and infant APOL1 genotypes on PE. As such, additional prospective studies are needed to help clarify the mode of inheritance and to evaluate the mechanism driven by APOL1 expression in either the fetus or placenta. Due to the use of archived specimens, our study did not have suitable and sufficient tissue for maternal genotyping and was unable to confirm the lack of association with the maternal APOL1 genotype. For the same reason, we were unable to genotype ancestry informative markers to eliminate possible population substructure as a confounder. In addition, we cannot rule out the APOL1 alleles are only markers in linkage disequilibrium with the true causal genetic variant.

\section{Conclusions}

This is a confirmatory report attributing a significant risk for PE associated with the fetal carriage of APOL1 variant alleles in African American women. Considering 
the high prevalence of these alleles in many African and African diaspora communities, future studies of both African American and African women will be useful in addressing a potentially significant cause of PE worldwide. Development of APOL1 genotyping strategies may be clinically useful in identifying mothers at risk for PE.

\section{Supplementary information}

Supplementary information accompanies this paper at https://doi.org/10. 1186/s12881-020-01048-4.

Additional file 1: Table 1. Summary of clinical information and pathological categories in the Ohio March of Dimes biobank. Table 2. Summary of inclusion/exclusion criteria. Table 3. Pathological variable summary statistics (chi square test). Table 4A. PE association with fetal APOL 1 genotype: Adjusted Model 1. Table 4B. PE association with fetal APOL 1 genotype: Adjusted Model 2. Table 4C. PE association with fetal APOL 1 genotype: Adjusted Model 3. Table 5A. Genotype comparisons for global chi square interactions. Table 5B. Association of APOL1 inheritance pattern with pathologic features (global chi square, $P$ values). Table 6. Pathologic features by APOL1 genotype.

\section{Abbreviations}

APOL1: Apolipoprotein 1; CKD: Chronic kidney disease; HELLP: Hemolysis, elevated liver enzymes, low platelet count; NOS: Not-otherwise-specified; PE: Preeclampsia

\section{Acknowledgements}

None

\section{Authors' contributions}

All authors have read and approved the manuscript. AKM: Data analysis, drafted manuscript, prepared figures and tables. TA: Data analysis and interpretation, edited manuscript. JFO: Study concept and design, performed genotyping, IRB approval, data analysis and interpretation, edited manuscript. JRS: Study concept and design, data interpretation, edited manuscript. SMW: Data analysis and interpretation, drafted and edited manuscript. RWR: Study concept and design, IRB approval, collected specimens, developed database, performed pathological evaluations, data analysis and interpretation, edited manuscript. LAB: Study concept and design, performed genotyping, data analysis and interpretation, drafted manuscript, prepared figures and tables, edited manuscript.

\section{Funding}

The Ohio March of Dimes biobank was funded by the March of Dimes Prematurity Research Center Ohio Collaborative.

\section{Availability of data and materials}

All data generated and analyzed during this study are included in this published article and its supplementary information files.

\section{Ethics approval and consent to participate}

This study was reviewed and approved by the Institutional Review Boards of University Hospitals and MetroHealth Medical Center of Case Western Reserve University. Institutional Review Board approval was given to collect human specimens and extract data from clinical records, and to use for this research. The need for consent was waived by the University of Hospitals Institutional Review Board as tissues were considered discard and only a deidentified data set was collected.

\section{Consent for publication}

Not applicable.

\section{Competing interests}

The authors declare no conflict of interest financial or otherwise for work presented in this manuscript.

\section{Author details}

'Department of Genetics and Genome Sciences, Case Western Reserve University School of Medicine, Cleveland, USA. ²Division of Neonatology, Department of Pediatrics, Metro Health Medical Center, Case Western Reserve University School of Medicine, Cleveland, USA. ${ }^{3}$ Departments of Inflammation and Immunity and Nephrology, Cleveland Clinic, Case Western Reserve University School of Medicine, Cleveland, USA. ${ }^{4}$ Department of Physiology and Biophysics, Case Western Reserve University School of Medicine, Cleveland, USA. ${ }^{5}$ Department of Population and Quantitative Health Sciences, Case Western Reserve University School of Medicine, Cleveland, USA. ${ }^{6}$ Departments of Pathology and Reproductive Biology, University Hospitals, Case Western Reserve University School of Medicine, Cleveland, $\mathrm{OH}, \mathrm{USA}$

Received: 18 January 2020 Accepted: 10 May 2020

Published online: 20 May 2020

\section{References}

1. Shahul S, Tung A, Minhaj M, Nizamuddin J, Wenger J, Mahmood E, Mueller A, Shaefi S, Scavone B, Kociol RD, et al. Racial Disparities in Comorbidities, Complications, and Maternal and Fetal Outcomes in Women With Preeclampsia/eclampsia. Hyperten Pregnancy. 2015;34(4):506-15.

2. Nakimuli A, Chazara O, Byamugisha J, Elliott AM, Kaleebu P, Mirembe F, Moffett A. Pregnancy, parturition and preeclampsia in women of African ancestry. Am J Obstetr Gynecol. 2014;210(6):510-520.e511.

3. ACOG Practice Bulletin No. 202: gestational hypertension and preeclampsia. Obstetr Gynecol. 2019;133(1):e1-e25.

4. Phipps EA, Thadhani R, Benzing T, Karumanchi SA. Pre-eclampsia: pathogenesis, novel diagnostics and therapies. Nat Rev Nephrol. 2019;15(5): 275-89.

5. Rosset S, Tzur S, Behar DM, Wasser WG, Skorecki K. The population genetics of chronic kidney disease: insights from the MYH9-APOL1 locus. Nat Rev Nephrol. 2011:7(6):313-26.

6. Pays $\mathrm{E}$, Vanhollebeke $\mathrm{B}$. Human innate immunity against African trypanosomes. Curr Opin Immunol. 2009;21(5):493-8.

7. Ma L, Shelness GS, Snipes JA, Murea M, Antinozzi PA, Cheng D, Saleem MA, Satchell SC, Banas B, Mathieson PW, et al. Localization of APOL1 protein and mRNA in the human kidney: nondiseased tissue, primary cells, and immortalized cell lines. J Am Soc Nephrol. 2015;26(2):339-48.

8. Madhavan SM, O'Toole JF, Konieczkowski M, Ganesan S, Bruggeman LA, Sedor JR. APOL1 localization in normal kidney and nondiabetic kidney disease. J Am Soc Nephrol. 2011;22(11):2119-28.

9. Duchateau PN, Pullinger CR, Cho MH, Eng C, Kane JP. Apolipoprotein L gene family: tissue-specific expression, splicing, promoter regions; discovery of a new gene. J Lipid Res. 2001;42(4):620-30.

10. Page NM, Butlin DJ, Lomthaisong K, Lowry PJ. The human apolipoprotein L gene cluster: identification, classification, and sites of distribution. Genomics. 2001:74(1):71-8.

11. Monajemi H, Fontijn RD, Pannekoek H, Horrevoets AJ. The apolipoprotein L gene cluster has emerged recently in evolution and is expressed in human vascular tissue. Genomics. 2002;79(4):539-46.

12. Bruggeman LA, Wu Z, Luo L, Madhavan SM, Konieczkowski M, Drawz PE, Thomas DB, Barisoni L, Sedor JR, O'Toole JF. APOL1-G0 or APOL1-G2 Transgenic Models Develop Preeclampsia but Not Kidney Disease. J Am Soc Nephrol. 2016:27(12):3600-10.

13. Elliott SE, Parchim NF, Liu C, Xia Y, Kellems RE, Soffici AR, Daugherty PS. Characterization of antibody specificities associated with preeclampsia. Hypertension. 2014;63(5):1086-93.

14. Ruis-Gonzalez MD, Canete MD, Gomez-Chaparro UL, Abril N, Canete R, Lopez-Barea J. Alterations of protein expression in serum of infants with intrauterine growth restriction and different gestational ages. J Proteomics. 2015;119:169-82.

15. Wen Q, Liu LY, Yang T, Alev C, Wu S, Stevenson DK, Sheng G, Butte AJ, Ling XB. Peptidomic Identification of Serum Peptides Diagnosing Preeclampsia. Plos One. 2013;8(6):e65571

16. Harrison GA, Humphrey KE, Jones N, Badenhop R, Guo G, Elakis G, Kaye JA, Turner RJ, Grehan M, Wilton AN, et al. A genomewide linkage study of preeclampsia/eclampsia reveals evidence for a candidate region on $4 \mathrm{q}$. Am J Hum Genet. 1997;60(5):1158-67.

17. Johnson MP, Brennecke SP, East CE, Goring HH, Kent JW Jr, Dyer TD, Said JM, Roten LT, Iversen AC, Abraham LJ, et al. Genome-wide association scan 
identifies a risk locus for preeclampsia on 2q14, near the inhibin, beta B gene. PloS One. 2012;7(3):e33666.

18. Lachmeijer AM, Arngrimsson R, Bastiaans EJ, Frigge ML, Pals G, Sigurdardottir S, Stefansson H, Palsson B, Nicolae D, Kong A, et al. A genome-wide scan for preeclampsia in the Netherlands. Eur J Hum Genet. 2001;9(10):758-64.

19. Laivuori H, Lahermo P, Ollikainen V, Widen E, Haiva-Mallinen L, Sundstrom H, Laitinen T, Kaaja R, Ylikorkala O, Kere J. Susceptibility loci for preeclampsia on chromosomes 2p25 and 9p13 in Finnish families. Am J Hum Genet. 2003;72(1):168-77.

20. Sampson MG, Robertson CC, Martini S, Mariani LH, Lemley KV, Gillies CE, Otto EA, Kopp JB, Randolph A, Vega-Warner V, et al. Integrative Genomics Identifies Novel Associations with APOL1 Risk Genotypes in Black NEPTUNE Subjects. J Am Soc Nephrol. 2015;27(3):814-23.

21. Robertson CC, Gillies CE, Putler RK, Ng D, Reidy KJ, Crawford B, Sampson MG. An investigation of APOL1 risk genotypes and preterm birth in African American population cohorts. Nephrol Dial Transplant. 2016;32(12):2051-8.

22. Reidy KJ, Hjorten RC, Simpson CL, Rosenberg AZ, Rosenblum SD, Kovesdy CP, Tylavsky FA, Myrie J, Ruiz BL, Haque S, et al. Fetal-Not Maternal-APOL1 Genotype Associated with Risk for Preeclampsia in Those with African Ancestry. Am J Hum Genet. 2018;103(3):367-76.

23. Khong TY, Mooney EE, Ariel I, Balmus NC, Boyd TK, Brundler MA, Derricott $H$ Evans MJ, Faye-Petersen OM, Gillan JE, et al. Sampling and Definitions of Placental Lesions: Amsterdam Placental Workshop Group Consensus Statement. Arch Pathology Lab Med. 2016;140(7):698-713.

24. Bruggeman LA, O'Toole JF, Ross MD, Madhavan SM, Smurzynski M, Wu K, Bosch RJ, Gupta S, Pollak MR, Sedor JR, et al. Plasma apolipoprotein L1 levels do not correlate with CKD. J Am Soc Nephrol. 2014;25(3):634-44.

25. Limou S, Dummer PD, Nelson GW, Kopp JB, Winkler CA. APOL1 toxin, innate immunity, and kidney injury. Kidney Int. 2015;88(1):28-34.

26. Bendon RW. Nosology: infarction hematoma, a placental infarction encasing a hematoma. Hum Pathol. 2012;43(5):761-3.

27. Fitzgerald B, Shannon P, Kingdom J, Keating S. Rounded intraplacenta haematomas due to decidual vasculopathy have a distinctive morphology. J Clin Pathol. 2011;64(8):729-32.

28. Leavey K, Benton SJ, Grynspan D, Kingdom JC, Bainbridge SA, Cox BJ. Unsupervised Placental Gene Expression Profiling Identifies Clinically Relevant Subclasses of Human Preeclampsia. Hypertension. 2016;68(1):13747.

29. Benton SJ, Leavey K, Grynspan D, Cox BJ, Bainbridge SA. The clinical heterogeneity of preeclampsia is related to both placental gene expression and placental histopathology. Am J Obstetr Gynecol. 2018, 219;(6):604.e60125.

30. Chaiworapongsa T, Chaemsaithong P, Yeo L, Romero R. Pre-eclampsia part 1: Current understanding of its pathophysiology. Nat Rev Nephrol. 2014; 10(8):466-80.

\section{Publisher's Note}

Springer Nature remains neutral with regard to jurisdictional claims in published maps and institutional affiliations.

Ready to submit your research? Choose BMC and benefit from:

- fast, convenient online submission

- thorough peer review by experienced researchers in your field

- rapid publication on acceptance

- support for research data, including large and complex data types

- gold Open Access which fosters wider collaboration and increased citations

- maximum visibility for your research: over $100 \mathrm{M}$ website views per year

At $\mathrm{BMC}$, research is always in progress.

Learn more biomedcentral.com/submissions 